\title{
Análisis de los recursos, usos y competencias tecnológicas del profesorado universitario para comprender y mejorar el proceso de aprendizaje del alumnado
}

\author{
Julio Barroso Osuna ${ }^{1}$ (D) @ \\ Vissy Yanet Matos Alcántara 2 (D) @ \\ Sonia Aguilar Gavira ${ }^{3}$ (D) @ \\ ${ }^{1}$ Universidad de Sevilla, España; ${ }^{2}$ Pontificia Universidad Católica Madre y Maestra, República Dominicana; \\ ${ }^{3}$ Universidad de Cádiz, España
}

Resumen. Las Tecnologías de la Información y la Comunicación suponen una valiosa fuente de interacción, construcción y difusión del conocimiento para el alumnado, aunque para ello, debe producirse una conversión del papel docente, abandonándose como eje vertebrador de la información y el conocimiento y donde la adquisición de unas competencias pedagógicas adquiere igual o mayor importancia que la tecnológica. El presente artículo tiene como finalidad conocer las posibles barreras que dificultan el aprendizaje del alumnado a través de las TIC. Para ello, ofreceremos los resultados alcanzados en una investigación llevada a cabo en la Pontificia Universidad Católica Madre y Maestra, en la ciudad de Santo Domingo, donde se analizaron los recursos tecnológicos disponibles, uso que se hace de ellos, así como la actitud y formación del profesorado. Se trata de una investigación descriptiva, con una metodología mixta donde se combinan técnicas cualitativas y cuantitativas. Según los resultados alcanzados, la formación recibida por el profesorado es escasa y centrada básicamente en aspectos técnicos, lo que dificulta el uso de las mismas con su alumnado desde un punto de vista pedagógico. La escasa competencia percibida en el propio profesorado provoca desmotivación y poca iniciativa para incorporarla en el proceso de enseñanza-aprendizaje.

Palabras clave: universidad; formación; profesorado; competencias tecnológicas; TPACK.

Análise dos recursos, usos e competências tecnológicas do corpo docente universitário para compreender e melhorar o processo de aprendizagem dos alunos

Resumen. As Tecnologias da Informação e Comunicação são uma fonte valiosa de interação, construção e disseminação de conhecimento para os alunos, embora para isso deva ocorrer uma transformação do papel docente, representando um eixo estruturador da informação e do conhecimento e onde a aquisição de competências pedagógicas adquira igual ou maior importância que a tecnológica. O objetivo deste artigo é conhecer as possíveis barreiras que dificultam a aprendizagem do aluno por meio das TIC. Para isso, ofereceremos os resultados alcançados em uma pesquisa realizada na Pontifícia Universidade Católica Madre y Maestra, na cidade de Santo Domingo, onde foram analisados os recursos tecnológicos disponíveis, o seu uso, bem como a atitude e a formação do corpo docente. Trata-se de uma pesquisa descritiva, com uma metodologia mista onde são combinadas técnicas qualitativas e quantitativas. De acordo com os resultados alcançados, a formação recebida pelos professores é limitada e centrada basicamente em aspectos técnicos, o que dificulta a sua utilização com seus alunos do ponto de vista pedagógico. A escassa competência observada no corpo docente causa desmotivação e pouca iniciativa para a sua inclusão no processo de ensino-aprendizagem.

Palavras-chave: universidade; formação; corpo docente; competências tecnológicas; TPACK.

Analysis of the resources, uses and technological competences of the university teaching staff to understand and improve the learning process of the students Abstract. Information and Communication Technologies are a valuable source of interaction, construction and dissemination of knowledge for students, although for this, there must be a conversion of the teaching role, abandoning as the backbone of information and knowledge and where the acquisition of pedagogical competences acquires equal or greater importance than the technological one. The purpose of this 
article is to understand the possible barriers that hinder student learning through ICT. For this, we will offer the results achieved in a research carried out at the Pontifical Catholic University Madre y Maestra, in the city of Santo Domingo, where the available technological resources, use of them, as well as attitude and training were analyzed of the teaching staff It is a descriptive research, with a mixed methodology where qualitative and quantitative techniques are combined. According to the results achieved, the training received by teachers is limited and basically focused on technical aspects, which makes it difficult to use them with their students from a pedagogical point of view. The scarce perceived competence in the teaching staff causes demotivation and little initiative to incorporate it into the teaching-learning process.

Keywords: University, training, teaching staff, technological competences, TPACK.

\section{INTRODUCCIÓN}

El desarrollo tecnológico ha supuesto grandes cambios en todas las esferas de nuestra vida, enfrentándonos a una sociedad en continuo cambio, inestable y dinámica. EI siglo XXI requiere ciudadanos formados en el conocimiento y uso de las mismas, garantizando así una participación activa en la actual sociedad web 2.0., y donde el profesorado tiene entre sus competencias el promover desde el contexto universitario su uso (Federico y Agresti, 2017; Gutiérrez, 2014). En esta línea nos gustaría señalar las palabras de Pérez (2012), con las que el autor insiste en la necesidad de establecer ciertos cambios en el sistema educativo:

(...) cambiar la mirada, de reinventar la escuela. Las reformas parciales sin sentido global ya no son suficientes. La explosión exponencial y acelerada de la información en la era digital requiere reconsiderar de manera sustancial el concepto de aprendizaje y los procesos de enseñanza. Demasiados docentes parecemos ignorar la relevancia extrema de esta nueva exigencia en nuestra tarea profesional (p. 68-69).

Aunque la presencia de las tecnologías cada vez es mayor en nuestro centros educativos, su incorporación según estudios realizados por (Arancibia, Cosimo, Casanoba, 2018; Barrera-Osorio y Linden, 2009; European Commission, 2008; Martínez, López-Martín y Pérez-Carbonell, 2018) no han provocado mejoras en la práctica educativa y, por ende, en el aprendizaje del alumnado. Su incorporación ha estado centrada en la mejora de infraestructuras tecnológicas, olvidándose de un aspecto fundamental para hacer un buen uso educativo de las mismas, la formación del profesorado tanto en aspectos técnicos como pedagógicos. Una formación insuficiente que ha dado lugar a un mal uso de la misma o a la desconfianza por parte del profesorado para incluirlas en su práctica docente (Banlankast y Blamire, 2007; Gray y Lewis, 2009). Aunque en muchas ocasiones se suele asociar tecnología con innovación, lo cierto es que el uso de las mismas no garantiza una mejora del proceso educativo si se continúa haciendo lo 
mismo que con una metodología tradicional, convirtiéndose las plataformas institucionales en meros repositorios de contenidos. Si deseamos una verdadera incorporación de dichas herramientas en el contexto educativo, es un requisito prioritario, la formación del profesorado universitario en competencias tecnológicas, así como pedagógicas. Cuando hablamos de competencia digital, hacemos referencia a las habilidades, conocimientos y actitudes que el usuario debe adquirir tanto en el manejo tecnológico, informacional y de comunicación, de forma que permita una utilización de las herramientas práctica y útil. Son diversos los estudios que han manifestado que la formación del profesorado llevada a cabo hasta el momento en dichos recursos no ha sido apropiada (Arancibia et al., 2017; Cabero, 2004; Cabero y Barroso, 2016; Llorente, 2008).

Hablar de competencias en Tecnología de la Información y la Comunicación (de ahora en adelante TIC) por parte del profesorado hace referencia "al conjunto de conocimientos y habilidades necesarias que este debe poseer para utilizar estas herramientas tecnológicas como unos recursos educativos más integrados en su práctica diaria" (Suárez et al., 2012, p. 294). Es más que evidente los beneficios que aporta las TIC al proceso de enseñanza-aprendizaje en nuestras universidades. Entre otros autores, Poore (2013, p. 6-9) realiza una clasificación de los beneficios que ofrece las herramientas, como:

1. Beneficios intelectuales como: a) análisis, interpretación, síntesis y crítica; b) validación y evaluación; c) alfabetización tradicional; d) alfabetización visual; e) alfabetización en medios $y, f)$ alfabetización funcional.

2. Beneficios para la comunicación, colaboración, participación y socialización: a) comunicación: b) trabajo en equipo y colaborativo; c) participación e integración; d) pensar en el receptor; e) aprender conductas apropiadas; f) investigar y, g) diversidad de opiniones.

3. Beneficios motivacionales como son: a) propiedad y control; b) aumento de esfuerzo; c) respuesta de receptores múltiples; d) autopublicación y, e) creatividad.

4. Beneficios de organización y administrativos debido a: a) Fácil de obtener feedback; b) seguimiento del aprendizaje del estudiante; c) accesibilidad fuera del centro; d) comunicación con padres; e) facilidad de presentación de los trabajos y, f) organización. 
Son diversas las investigaciones (Angulo et al., 2015; Barroso y Padrón, 2014; Cabero y Barroso, 2016; Carrera y Coiduras, 2012; Cejas et al., 2016; Marín et al., 2014; Pozos, 2015; Prendes y Gutiérrez, 2013) que se han dedicado en los últimos tiempos al análisis de las competencias tecnológicas del profesorado en educación superior. Para Area y Guarro (2012) son cinco las dimensiones (instrumental, cognitiva, comunicativa, axiológica y emocional) implicadas en el aprendizaje, adquisición y desarrollo de estas competencias y que debieran ser cultivadas y trabajadas en todo proyecto educativo de alfabetización.

No menos importancia ha adquirido los estudios (Kaya, Emre y Kaya, 2013; Leiva, Ugalde y Llorente-Cejudo, 2018; Roig y Flores, 2014) que se han centrado en el estudio del modelo TPACK creado por Mishra y Koehler (2006) y acrónimo de "Technological Pedagogical Content Knowledge". Dicho modelo supone el resultado de la adecuada combinación de conocimiento tecnológico, disciplinar y didáctico-pedagógico que debe ser adquirido por parte del docente para aprovechar el gran potencial que nos ofrece las TIC y desarrollar un aprendizaje activo, participativo y centrado en el alumnado, siendo capaz de seleccionar las tecnologías más apropiadas y con valor en los diferentes momentos educativos. La incorporación educativa de estos instrumentos tecnológicos podríamos hacerla desde tres posiciones (Cabero, 2014): a) Desde la perspectiva de las TIC: recurso facilitadores y transmisores de información y recursos educativos para los estudiantes, pudiendo ser ajustado a las necesidades y singularidades de los sujetos, pudiendo conseguir una verdadera formación audiovisual, multimedia e hipertextual; b) Desde la posición de las TAC: implica su utilización como instrumentos facilitadores del aprendizaje y la difusión del conocimiento. Herramientas para la realización de actividades para el aprendizaje, y; c) desde la posición de las TEP: como instrumentos para la participación y la colaboración de docentes y discentes. El aprendizaje no solo tiene una dimensión individual, sino también social, ya que la formación implica aprender en comunidad y ser capaz de interactuar y colaborar para construir el conocimiento.

Si se ofreciera una mayor formación del profesorado, más allá de aspectos técnicos, facilitaríamos que el alumnado pudiera construir su conocimiento desde el principio de actividad, atendiendo a su vez, a la diversidad. Para ello, es primordial conocer cómo aprende el alumnado y poder dar respuesta a sus características individuales. Diversos autores define el Learning Analytics (LA), como la herramienta que permite al profesorado recoger, analizar información de su alumnado y su contexto, con el objetivo de comprender y dar respuesta a sus necesidades, favoreciendo así su aprendizaje (Buckingham y Ferguson, 2012; Díaz, 2017; Johnson et al., 2013; Johnson, Adams, Estrada y Freeman, 2014; Rojas-Castro, 2017; Siemens y Long, 2013) y por tanto, el éxito educativo de todos los discentes. Esto de- 
muestra la necesidad de un enfoque centrado en el Diseño Universal para el aprendizaje, el cual aprovecha el gran potencial de los recursos tecnológicos, permitiendo ofrecer al alumnado "diferentes formas de acceso a un contenido, diferentes posibilidades de interactuar con él y de mostrar que se ha producido el aprendizaje" (Pastor, 2012, p.8). De esta forma eliminaríamos muchas de las barreras con las que se encuentran, ofreciendo "un diseño pensado para todos y todas y no para la mayoría, que permita ser utilizado y favorezca el proceso de aprendizaje de cada uno de los y las discentes, considerando su individualidad, independientemente de cualquier necesidad específica" (Aguilar y Benítez, 2017, p.4).

\section{Metodología}

Nos encontramos ante una investigación de tipo descriptiva, con un enfoque mixto, en el que se utilizan tanto métodos cuantitativos como cualitativos según los objetivos establecidos.

\subsection{Objetivos del estudio}

La investigación que presentamos tiene como objetivo principal conocer si las tecnologías incorporadas y el uso que se hace de ellas favorecen el proceso de aprendizaje del alumnado universitario y, por ende, la calidad del proceso educativo. Dicho objetivo general, se concreta en los siguientes objetivos específicos:

- Conocer las herramientas y recursos tecnológicos disponibles en la universidad y el grado de satisfacción del profesorado en relación a los mismos.

- Valorar la actitud y la tendencia del profesorado a la hora de aplicar los medios y recursos tecnológicos en los procesos de enseñanza-aprendizaje.

- Conocer la formación recibida y detectar las necesidades del profesorado para responder a una adecuada inclusión de las TIC en las aulas universitarias.

- Identificar las principales barreras o limitaciones con las que se encuentra el profesorado para aplicar las TIC en el proceso educativo. 


\subsection{Población y muestra}

Desde un punto de vista cuantitativo, la muestra quedó configurada por 143 docentes de la Pontificia Universidad Católica Madre y Maestra (PUCMM), del campus Santo Tomás de Aquino (CSTA), siendo mayor el porcentaje de mujeres (56\%) que el de hombres (44\%). En el caso cualitativo, se entrevistó a ocho informantes claves, entre directores de departamentos y personal de Tecnología Educativa. Para ambos casos, se empleó un muestreo no probabilístico intencional, aquel seleccionado por el propio investigador (Albert, 2006; Sabariego, 2004).

\subsection{Instrumentos}

Para recabar información y poder dar respuesta a los objetivos planteados se lleva a cabo una metodología mixta. Por un lado, se diseñó dos cuestionarios, los cuales serían aplicados al profesorado universitario. Mediante la aplicación del primer cuestionario, dividido este en dos grandes dimensiones, se pretende: a) Conocer la conectividad y acceso a los recursos tecnológicos, actividades que realizan utilizando las TIC, propósito con el que la utiliza en su actividad docente, barreras que dificultad su uso, y; b) Nivel de conocimiento en TIC, formación recibida, lugar y tiempo de formación recibida y obstáculos encontrados en su proceso de formación en TIC. Mediante la aplicación del segundo cuestionario se pretende: a) Evaluar las actitudes de los profesores hacia la integración de las TIC en las aulas. Para ello, se utilizó un cuestionario ya elaborado y validado con anterioridad por (Tejedor et al., 2009) el cual constaba de 24 ítems, divididos estos en tres dimensiones: cognitivo, afectivo y comportamental y bajo una escala de valoración tipo Likert de cuatro categorías, del 1 al 4 si el ítem era positivo y del 4 al 1 si el ítem era negativo.

La validez del instrumento del primer cuestionario se lleva a cabo mediante la técnica de juicio de expertos, llevando a cabo un muestreo no probabilístico de tipo intencional u opinático "determinado por la selección de los sujetos particulares que son expertos en un tema o relevantes como fuentes importantes de información según criterios establecidos previamente" (Llorente-Cejudo, 2008, p.191) por el propio investigador. En el caso concreto del citado estudio se opta por seleccionar a los expertos bajo una serie de criterios, para lo cual se elabora un biograma y en el que se tendría en cuenta aspectos, como: su experiencia en didáctica educativa, metodología de la investigación, integración de TIC en los procesos de enseñanza y aprendizaje y en formación del profesorado en TIC. 
Con respecto al número de expertos y de acuerdo con las aportaciones de Cabero y Barroso (2013) su selección depende muchas veces de: a) La posibilidad de poseer expertos suficientes con claras referencias hacia la temática analizada; b) El evitar el menor número de pérdida de sujetos entre las dobles y triples vueltas que se hace necesario en algunos estudios; c) El volumen de trabajo que seamos capaces de mover; d) La facilidad para acceder a los expertos, y; e) La rapidez con que debamos ofrecer los resultados preliminares, sobre todo en estudios de varias vueltas, para evitar la desmotivación en la participación en el estudio de los «expertos». Teniendo en cuenta las aportaciones de dichos autores, el instrumento fue evaluado por un total de 22 profesores pertenecientes a diferentes universidades. Son diversos los métodos para recoger la información de los expertos seleccionados (Barroso y Cabero, 2010; Cabero y Barroso, 2013; Cabero y Marín, 2013). De todos ellos, se opta por el de agregación individual, obteniendo información individual de ellos sin que estén en contacto. Asimismo, para alcanzar el grado de fiabilidad se utiliza el Alfa de Cronbach, alcanzando una puntuación significativa para las variables "Valore la disponibilidad de las TIC en su universidad", "de los recursos tecnológicos mencionados cuáles utiliza en su labor docente y con qué frecuencia" e "Indique el nivel de conocimiento que tiene de las herramientas TIC que se presentan" de 0.867 , 0.871 y 0.939 respectivamente. Para alcanzar la fiabilidad en el contexto del segundo cuestionario, relacionado este con la "Actitud de los profesores hacia la integración de las TIC en las aulas" ya elaborado por (Tejedor et al., 2009), se realizó un estudio piloto, proporcionando el cuestionario a los mismos 22 docentes del primer cuestionario, obteniendo un coeficiente de Cronbach de 0.887 , por lo que se evidencia un alto nivel de fiabilidad del instrumento.

Mediante la entrevista semiestructurada se pretende ahondar así como contractar los resultados alcanzados mediante el cuestionario. Mediante su aplicación se obtenía información relativa a la "disponibilidad de TIC en la universidad", "Uso didáctico de las TIC", "Formación y Necesidades formativas en TIC del profesorado" y "Actitud de los profesores y estudiantes hacia las TIC". Los ítems fueron validados por investigadores experimentados, a los cuales se les pidió que comentaran sobre la idoneidad de las preguntas y su potencial para provocar respuestas pertinentes al tema de la investigación y a los objetivos generales de la investigación. 


\section{Análisis y resultados}

Como punto de partida, daremos a conocer "los aspectos técnicos y recursos tecnológicos disponibles en la universidad" con los que cuenta el profesorado para desarrollar ese proceso de enseñanza-aprendizaje con su alumnado. Como se puede apreciar en la Tabla 1, el profesorado considera que el mayor recurso con el que cuentan, con un $70,1 \%$, es el correo institucional para poder comunicarse con el alumnado, con un $69,2 \%$ los proyectores de las aulas, con un $60,1 \%$ los ordenadores, la web docente y el calendario virtual, ambos con un $58,7 \%$ y la conexión a Internet en las zonas del profesorado con $56.6 \%$. Sin embargo, consideran que son deficientes la conexión wifi con $62,9 \%$ en el centro, la conexión wifi en las aulas con un $60,8 \%$, con un $47.6 \%$ la plataforma de la universidad, con un $46.9 \%$ las salas de informática y con un $37.1 \%$ los entornos de trabajo colaborativo. Por último, un gran número del profesorado afirma desconocer con un $42 \%$ o no existir con un $25,2 \%$ software educativo.

Tabla 1. Frecuencias y porcentajes de la variable "Aspectos técnicos y recursos tecnológicos en la universidad"

Lo

No existe desconoce Deficiente Suficiente

\section{Ordenadores}

Sala de Informática

Proyector en las aulas

Software educativo

Conexión a Internet en las aulas

Conexión a Internet en los laboratorios

Conexión Wifi

Conexión a Internet en las zonas del profesorado

Conexión a Internet en la biblioteca

Web docente

Web del alumnado

Plataforma de la Universidad

Entornos de trabajo colaborativo

Correo institucional

Sala de Videoconferencia

Equipo de grabación de vídeo

Equipo de sonido

Agenda/Calendario virtual

Acceso a bases de datos especializadas

\begin{tabular}{cccccccc}
$\mathrm{f}$ & $\%$ & $\mathrm{f}$ & $\%$ & $\mathrm{f}$ & $\%$ & $\mathrm{f}$ & $\%$ \\
\hline 0 & 0.0 & 0 & 0.0 & 57 & 39.9 & 86 & 60.1 \\
0 & 0.0 & 0 & 0.0 & 67 & 46.9 & 76 & 53.1 \\
0 & 0.0 & 0 & 0.0 & 44 & 30.8 & 99 & 69.2 \\
36 & 25.2 & 60 & 42.0 & 31 & 21.7 & 16 & 11.2 \\
0 & 0.0 & 0 & 0.0 & 87 & 60.8 & 56 & 39.2 \\
1 & 0.7 & 26 & 18.2 & 59 & 41.3 & 57 & 39.9
\end{tabular}

$\begin{array}{llllllll}1 & 0.7 & 0 & 0.0 & 90 & 62.9 & 52 & 36.4\end{array}$

$\begin{array}{llllllll}0 & 0.0 & 16 & 11.2 & 46 & 32.2 & 81 & 56.6\end{array}$

$\begin{array}{llllllll}5 & 3.5 & 16 & 11.2 & 52 & 36.4 & 70 & 49.0\end{array}$

$\begin{array}{llllllll}12 & 8.4 & 14 & 9.8 & 33 & 23.1 & 84 & 58.7\end{array}$

$\begin{array}{llllllll}15 & 10.5 & 26 & 18.2 & 25 & 17.5 & 77 & 53.8\end{array}$

$\begin{array}{llllllll}2 & 1.4 & 3 & 2.1 & 68 & 47.6 & 70 & 49.0\end{array}$

$\begin{array}{llllllll}22 & 15.4 & 32 & 22.4 & 53 & 37.1 & 36 & 25.2\end{array}$

$\begin{array}{llllllll}3 & 2.1 & 4 & 2.8 & 35 & 24.5 & 101 & 70.6\end{array}$

$\begin{array}{llllllll}19 & 13.3 & 27 & 18.9 & 50 & 35.0 & 47 & 32.9\end{array}$

$\begin{array}{lllllllll}21 & 14.7 & 55 & 38.5 & 38 & 26.6 & 29 & 20.3\end{array}$

$\begin{array}{llllllll}5 & 3.5 & 28 & 19.6 & 34 & 23.8 & 76 & 53.1\end{array}$

$\begin{array}{llllllll}7 & 4.9 & 11 & 7.7 & 41 & 28.7 & 84 & 58.7\end{array}$

$\begin{array}{llllllll}15 & 10.5 & 26 & 18.2 & 29 & 20.3 & 73 & 51.0\end{array}$ 
En el Figura 1, se puede apreciar de manera generalizada la apreciación de los docentes hacia la infraestructura tecnológica de la universidad. El $72 \%$ de los profesores encuestados afirma que los recursos tecnológicos disponibles son insuficientes, un $26,6 \%$ lo desconoce y tan sólo un $0,7 \%$ afirman ser suficiente.

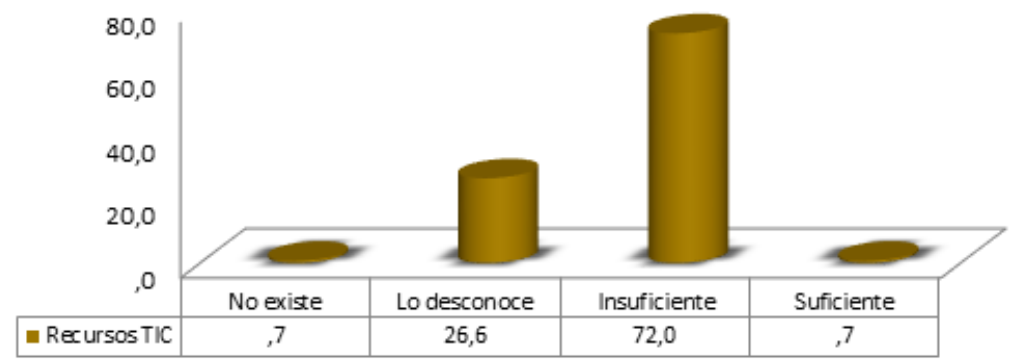

Figura 1. Disponibilidad de recursos tecnológicos en la universidad según los docentes.

Una vez analizado los recursos disponibles en la universidad, nos centraremos en conocer cuáles son utilizados por el profesorado en su acción formativa y con qué frecuencia (Véase Tabla 2). En relación al primer ítem "Ordenadores" el 86\% afirma que lo hace "Siempre" ( $f=89 ; 62.2 \%$ ) o "Casi siempre" ( $\mathrm{f}=34 ; 23.8 \%$ ), frente al $14 \%$ que aseveró utilizarlas "Algunas veces" ( $\mathrm{f}=18 ; 12.6 \%)$ o "Nunca" ( $\mathrm{f}=2 ; 1.4 \%)$. Los "Proyectores en las aulas" suelen ser utilizados "Siempre o Casi siempre" por el 78.4\%. En contraposición, un $21.7 \%$ afirma que lo utiliza "Algunas veces o Nunca". Respecto al ítem "Laboratorios de informática", el $25.9 \%$ afirma que lo hace "Siempre" ( $f=22 ; 15.4 \%)$ o "Casi Siempre" (15; 10.5\%), frente al $74.2 \%$ que aseveró utilizarlas "Algunas veces" ( $f=47 ; 32.9 \%$ ) o "Nunca" $(f=59 ; 41.3 \%)$. En relación al "Móvil o Smartphone", el 32.2\% afirma que lo utiliza Siempre ( $f=17 ; 11.9 \%)$ o Casi siempre ( $f=29 ; 20.3 \%)$, mientras, el $67.9 \%$ dice que los utiliza Algunas veces $(f=36 ; 25.2 \%)$ o Nunca $(f=$ $61 ; 42.7 \%$ ). Si analizamos los resultados alcanzados bajo el ítem "Uso de Internet en las aulas", un 55.3\% del profesorado dice usarlo "Siempre" ( $f=$ $42 ; 29.4 \%$ ) o Casi siempre" ( $f=37 ; 25.9 \%$ ), mientras que el $44.7 \%$ afirma que la utiliza "Algunas veces" ( $f=29 ; 20.3 \%$ ) o "Nunca" ( $f=35 ; 24.5 \%$ ). En el caso de los laboratorios, el $43.4 \%$ afirman utilizar internet Siempre $(f=37 ; 25.9 \%)$ o Casi siempre ( $f=25 ; 17.5 \%)$, en contraposición al $53.7 \%$ dice utilizarlo Algunas veces $(f=35 ; 24.5 \%)$ o Nunca $(f=46 ; 32.2 \%)$. Con respecto a la "Conexión Wifi", aunque los docentes manifiestan la lentitud de la misma, el $58.8 \%$ dicen utilizarla "Siempre" ( $f=52 ; 36.45)$ o "Casi siempre" ( $f=32 ; 22.4 \%)$, frente al $41.2 \%$ que dicen utilizarla "Algunas veces" ( $f=36 ; 25.2)$ o "Nunca" ( $f=23 ; 16.1 \%$ ). En el ítem "utilización de Internet en los cubículos de profesores", el $46.9 \%$ de los docentes lo utilizan 
"Siempre" ( $f=53 ; 37.1 \%$ ) o "Casi siempre" ( $f=23 ; 16.1 \%$ ), mientras que el $53.2 \%$ lo utilizan "Algunas veces" ( $f=23 ; 16.1 \%$ ) o "Nunca" ( $f=44$; $30.8 \%)$. En cuanto al uso de "Internet en el salón de profesores", el $37.8 \%$ de los docentes dicen utilizarlo Siempre $(f=32 ; 22.4 \%)$ o Casi siempre $(f=$ $22 ; 15.4 \%$ ), mientras que el $62.3 \%$ afirma utilizarlo Algunas veces ( $f=38$; $26.6 \%)$ o Nunca $(f=51 ; 35.7 \%)$.

En el ítem "El acceso a Internet desde la biblioteca", el 32.9\% dicen acceder Siempre $(f=29 ; 20.3 \%)$ o casi siempre ( $f=18 ; 12.6 \%)$ desde dicho lugar, mientras que la gran mayoría, el $67.2 \%$ dice acceder desde ahí solo Algunas veces $(f=38 ; 26.6 \%)$ o Nunca $(f=58 ; 40.6 \%)$. Con los mayores valores porcentuales, $62.3 \%$, el profesorado dice que utiliza la Web docente "Siempre" ( $f=50 ; 35 \%$ ) o "Casi siempre" ( $f=39 ; 27.3 \%$ ), mientras que el $37.7 \%$ la utiliza "Algunas veces" ( $f=18 ; 12.6 \%$ ) o "Nunca" ( $f=36 ; 25.2 \%)$. Ante el uso de la "Plataforma virtual", el 67.2\% afirma utilizarla "Siempre" $(f=62 ; 43.4 \%)$ o "Casi siempre" ( $f=34 ; 23.8 \%)$, frente al $32.8 \%$ que asevera utilizarla "Algunas veces" ( $f=26 ; 18.2 \%)$ o "Nunca" ( $f=21 ; 14.7 \%)$. Respecto al uso de "Recursos educativos abiertos", el 33.6\% afirma que los utiliza Siempre ( $f=21 ; 14.7 \%)$ o Casi siempre $(f=27 ; 18.9 \%)$, mientras que el $66.5 \%$ dice que los utiliza Algunas veces $(f=24 ; 16.8 \%$ ) o Nunca ( $f=71$; 49.7\%). En cuanto al "Correo institucional", el 65.8\% dice utilizarlo "Siempre" ( $f=66 ; 46.2 \%$ ) o "Casi siempre" ( $f=28 ; 19.6 \%)$, frente al $34.3 \%$ que dice utilizarlo "Algunas veces" ( $f=23 ; 16.1 \%)$ o "Nunca" $(f=26 ; 18.2 \%)$. Respecto al uso de "Herramientas Web 2.0 en sus clases", sólo un $20.3 \%$ de los profesores la utilizan Siempre $(f=12 ; 8.4 \%)$ o Casi siempre ( $f=17$; $11.9 \%$ ), frente al $79.7 \%$ que dicen utilizarla Algunas veces ( $f=18 ; 12.6 \%)$ o Nunca ( $f=96 ; 67.1 \%)$. En relación al ítem "uso de la Sala de videoconferencia", solo un $9.1 \%$ de los docentes suelen utilizarla Siempre $(f=7 ; 4.9 \%)$ o Casi siempre $(f=6 ; 4.2 \%)$, frente al $90.9 \%$ que afirma utilizarla Algunas veces $(f=36 ; 25.2 \%)$ o Nunca $(f=94 ; 65.7 \%)$. El ítem menos valorado es el que hace referencia a "Realidad aumentada". El 92.3\% de los docentes lo utilizan bajo la opción "Nunca" ( $f=132 ; 92.3 \%$ ), el $5.6 \%$ afirman que lo utiliza "Algunas veces" ( $f=8 ; 5.6 \%)$ y "Casi siempre" ( $f=3 ; 2.1 \%)$. La opción "Siempre" no fue seleccionada por ningún docente. Ante el uso de "Equipo de grabación de audio y vídeo", el 23.1\% afirman que lo utiliza "Siempre" $(f=19 ; 13.3 \%)$ o "Casi siempre" ( $f=14 ; 9.8 \%)$, frente al $76.9 \%$ que asegura utilizarlo "Algunas veces" ( $f=34 ; 23.8 \%$ ) o "Nunca" ( $f=76 ; 53.1 \%$ ). En cuanto a las "Base de datos especializadas", el $22.4 \%$ manifiesta que las utiliza "Siempre" ( $f=32 ; 22.4 \%$ ) o "Casi siempre" ( $f=24 ; 16.8 \%)$, frente al $60.9 \%$ que dice utilizarla "Algunas veces" ( $f=31 ; 21.7 \%$ ) o "Nunca" ( $f=$ $56 ; 39.2 \%)$. Otro de los recursos menos puntuados por el profesorado son los "Videojuegos", alcanzando los mayores valores porcentuales bajo la opción Nunca ( $f=130,90.9 \%$ ). 
Tabla 2. Frecuencias y porcentajes de la variable "Recursos TIC utilizados en su labor docente y con qué frecuencia"

\begin{tabular}{|c|c|c|c|c|c|c|c|c|}
\hline & \multicolumn{2}{|c|}{ Nunca } & \multicolumn{2}{|c|}{$\begin{array}{l}\text { Algunas } \\
\text { veces }\end{array}$} & \multicolumn{2}{|c|}{$\begin{array}{l}\text { Casi } \\
\text { siempre }\end{array}$} & \multicolumn{2}{|c|}{ Siempre } \\
\hline & $f$ & $\%$ & $f$ & $\%$ & $f$ & $\%$ & $f$ & $\%$ \\
\hline Ordenadores & 2 & 1.4 & 18 & 12.6 & 34 & 23.8 & 89 & 62.2 \\
\hline Proyector en las aulas & 6 & 4.2 & 25 & 17.5 & 41 & 28.7 & 71 & 49.7 \\
\hline Laboratorios de Informática & 59 & 41.3 & 47 & 32.9 & 15 & 10.5 & 22 & 15.4 \\
\hline Móvil o Smartphone & 61 & 42.7 & 36 & 25.2 & 29 & 20.3 & 17 & 11.9 \\
\hline Conexión a Internet en las aulas & 35 & 24.5 & 29 & 20.3 & 37 & 25.9 & 42 & 29.4 \\
\hline $\begin{array}{l}\text { Conexión a Internet en los labo- } \\
\text { ratorios }\end{array}$ & 46 & 32.2 & 35 & 24.5 & 25 & 17.5 & 37 & 25.9 \\
\hline Conexión Wifi & 23 & 16.1 & 36 & 25.2 & 32 & 22.4 & 52 & 36.4 \\
\hline $\begin{array}{l}\text { Conexión a Internet en las zonas } \\
\text { del profesorado }\end{array}$ & 44 & 30.8 & 23 & 16.1 & 23 & 16.1 & 53 & 37.1 \\
\hline $\begin{array}{l}\text { Conexión a Internet en la bi- } \\
\text { blioteca }\end{array}$ & 58 & 40.6 & 38 & 26.6 & 18 & 12.6 & 29 & 20.3 \\
\hline Web docente & 36 & 25.2 & 18 & 12.6 & 39 & 27.3 & 50 & 35.0 \\
\hline Plataforma de la Universidad & 21 & 14.7 & 26 & 18.2 & 34 & 23.8 & 62 & 43.4 \\
\hline Recursos Educativos Abiertos & 71 & 49.7 & 24 & 16.8 & 27 & 18.9 & 21 & 14.7 \\
\hline Correo institucional & 26 & 18.2 & 23 & 16.1 & 28 & 19.6 & 66 & 46.2 \\
\hline $\begin{array}{l}\text { Herramientas Web } 2.0 \text { (blog, } \\
\text { wiki,... }\end{array}$ & 96 & 67.1 & 18 & 12.6 & 17 & 11.9 & 12 & 8.4 \\
\hline Sala de videoconferencia & 94 & 65.7 & 36 & 25.2 & 6 & 4.2 & 7 & 4.9 \\
\hline Realidad aumentada & 13.2 & 92.3 & 8 & 5.6 & 3 & 2.1 & 0 & 0.0 \\
\hline $\begin{array}{l}\text { Equipo de grabación de audio } \\
\text { y vídeo. }\end{array}$ & 76 & 53.1 & 34 & 23.8 & 14 & 9.8 & 19 & 13.3 \\
\hline $\begin{array}{l}\text { Acceso a bases de datos espe- } \\
\text { cializadas }\end{array}$ & 56 & 39.2 & 31 & 21.7 & 24 & 16.8 & 32 & 22.4 \\
\hline Videojuegos & 13 & 90.9 & 7 & 4.9 & 6 & 4.2 & 0 & 0.0 \\
\hline
\end{tabular}

Tras los resultados precedentes, podemos afirmar que los recursos tecnológicos más utilizados por el profesorado en su labor docente son las computadoras ( $f=123,86 \%$ ), tanto de escritorio como portátiles, el proyector ( $f=112,78.4 \%$ ), la Plataforma de la Universidad $(f=96,67.2 \%)$ y el correo electrónico $(f=94,65.8 \%)$. Los menos utilizados son el teléfono móvil $(f=97$, $67.9 \%$ ), los recursos educativos abiertos $(f=94,66.5 \%$ ), las herramientas Web $2.0(f=114,79.7 \%)$, la sala de videoconferencia $(f=130,90.9 \%)$, la realidad aumentada $(f=132,92.3 \%$ ), los equipos de grabación de audio y video $(f=110,76.9 \%)$, y los videojuegos $(f=130,90.9 \%)$.

Otro de los objetivos a alcanzar con dicha investigación es conocer para qué suele utilizar el profesorado los recursos tecnológicos. En dicha variable, las personas encuestadas tienen la posibilidad de marcar varias opciones. En la Tabla 3 podemos ver los resultados alcanzados. 
Tabla 3. Frecuencias y porcentajes de la variable "Uso que hacen de las TIC el profesorado universitario"

\begin{tabular}{lcc}
\hline & Frecuencia (f) & Porcentaje (\%) \\
\hline $\begin{array}{l}\text { Prepara los materiales de las clases (presentaciones, } \\
\text { textos, gráficos, etc.) }\end{array}$ & 138 & 97.9 \\
Lleva el control de las calificaciones del alumnado & 126 & 89.4 \\
Consulta información en bases de datos, a través de & 118 & 83.7 \\
la Web & & \\
Publica y comparte información en la Web & 89 & 63.1 \\
Evalúa a los discentes & 88 & 62.4 \\
Elabora materiales didácticos en línea & 65 & 46.1 \\
Utiliza las bases de datos disponibles en su universidad & 51 & 36.2 \\
Participa en comunidades de aprendizaje & 63 & 44.7 \\
Utiliza recursos de Internet para enriquecer sus clases & 118 & 83.7 \\
Utiliza la plataforma solo para colgar recursos a sus & 55 & 39.0 \\
estudiantes & & \\
Se comunica con el alumnado & 116 & 82.3 \\
Realiza actividades de trabajo colaborativo & 46 & 32.6 \\
Gestiona y organiza mejor los contenidos y recursos & 95 & 67.4 \\
para sus alumnos. & & 63.1 \\
Trabaja los proyectos de sus clases & 89 & 891.5 \\
Total & 1257 & \\
\hline
\end{tabular}

Como podemos apreciar en la Tabla precedente, el mayor uso que el profesorado suele darle a las TIC es para preparar los materiales de clase como, presentaciones de PowerPoint ( $f=138,97.9 \%$ ), así como para llevar el control de las calificaciones del alumnado ( $f=126,89.4 \%)$, consultar bases de datos en la Web $(118,83.7 \%)$, comunicarse con los/as estudiantes ( $f=116$, $82.3 \%$ ) y buscar recursos en la Web para enriquecer sus clases ( $f=118$, $83.7 \%)$. Sin embargo, suelen hacer un menor uso de las TIC para realizar trabajos colaborativos ( $f=46,32.6 \%$ ), elaboración de materiales didácticos en línea $(f=65,46.15)$, la utilización de las bases de datos de la universidad $(f=51,36.2 \%)$ y participar en comunidades de aprendizaje ( $f=63,44.7 \%)$.

Los principales motivos o propósitos por los que suelen utilizar las TIC durante su práctica docente, podemos verlo en la Tabla 4. Según los resultados, y alcanzando los mayores porcentajes, el $84.5 \%$ de los docentes afirman utilizarla para motivar a los estudiantes, para clarificar e ilustrar conceptos con un $73.2 \%$, el $85.2 \%$ afirman utilizarla para facilitar la transferencia de conocimientos, así como mejorar el aprendizaje de los estudiantes, con un $80.3 \%$. Con la finalidad de retroalimentación suele ser utilizado por el $76.1 \%$ y el $53.5 \%$ para evaluar el aprendizaje. También, $74.6 \%$ expone 
utilizarla para propiciar el autoaprendizaje y el $80.3 \%$ afirma que su propósito es mantener comunicación con el alumnado. Otro aspecto altamente valorado es su utilización para implementar una metodología más creativa (74.6\%). Con menores porcentajes, pero no menos relevantes, la utilizan para el desarrollo de actividades de práctica (66.2\%), para apoyar el desarrollo de las lecciones (62.0\%), crear y supervisar proyectos de clases (55.6\%), promover el trabajo en equipo (53.5\%) y fomentar el trabajo colaborativo (59.9\%).

Tabla 4. Frecuencias y porcentajes de la variable "propósito de utilizar las TIC en su actividad docente"

\begin{tabular}{lcc}
\hline & Frecuencia (f) & Porcentaje (\%) \\
\hline Motivar al alumnado & 120 & $84.5 \%$ \\
Clarificar e ilustrar conceptos & 104 & $73.2 \%$ \\
Facilitar transferencia de conocimientos & 121 & $85.2 \%$ \\
Mejorar el aprendizaje de los estudiantes & 114 & $80.3 \%$ \\
Retroalimentar & 108 & $76.1 \%$ \\
Evaluar el aprendizaje & 76 & $53.5 \%$ \\
Propiciar el autoaprendizaje & 106 & $74.6 \%$ \\
Mantener comunicación con los alumnos & 114 & $80.3 \%$ \\
Fomentar el trabajo colaborativo & 85 & $59.9 \%$ \\
Promover el trabajo en equipo & 76 & $53.5 \%$ \\
Desarrollo de actividades de práctica & 94 & $66.2 \%$ \\
Apoyar el desarrollo de las lecciones & 88 & $62.0 \%$ \\
Crear y supervisar proyectos de clases & 79 & $55.6 \%$ \\
Implementar una metodología más creativa & 106 & $74.6 \%$ \\
Total & 142 & $100 \%$ \\
\hline
\end{tabular}

Así mismo, se considera fundamental conocer los factores que dificultan que el profesorado hagan uso de las TIC en su práctica docente (Véase Tabla 5). Según los encuestados, y con el mayor porcentaje alcanzado, con un $63,5 \%$, la principal barrera con la que se encuentran es una conexión a Internet muy lenta. El segundo factor, y bajo la opción "Otros" en dicha variable, los docentes exponen la falta de tiempo con un $54.7 \%$. El tercer y cuarto factor importante, con un 40,1\%, es su escasa formación para hacer uso de las mismas y la falta de apoyo institucional y el soporte técnico insuficiente, ambos con un 38.7\%. Por otro lado, y en menor medida, dichas dificultades se deben al número de laptops insuficiente (29.9\%), ordenadores obsoletos (28.5\%), número de ordenadores insuficientes (27\%), falta de experiencia (26.3\%), desconocimiento técnico (24.1\%), desconocimiento del uso didáctico de las TIC (22.6\%), muchos estudiantes por grupo (34.3\%), soporte pedagógico insuficiente (26.3\%) y falta de interés de los alumnos (29.2\%). 
Tabla 5. Frecuencias y porcentajes de la variable "Razones que dificultan el uso de las TIC en su labor docente"

\begin{tabular}{lcc}
\hline & Frecuencia (f) & Porcentaje (\%) \\
\hline Ordenadores insuficientes & 37 & $27 \%$ \\
Cantidad de laptops insuficiente & 41 & $29.9 \%$ \\
Conexión a Internet muy lenta & 87 & $63.5 \%$ \\
Ordenadores obsoletos & 39 & $28.5 \%$ \\
Poca formación en TIC & 55 & $40.1 \%$ \\
Falta de experiencia & 36 & $26.3 \%$ \\
Desconocimiento técnico & 33 & $24.1 \%$ \\
Desconocimiento del uso didáctico de las TIC & 31 & $22.6 \%$ \\
Muchos estudiantes por grupo & 47 & $34.3 \%$ \\
Soporte técnico insuficiente & 53 & $38.7 \%$ \\
Soporte pedagógico insuficiente & 36 & $26.3 \%$ \\
Falta de apoyo institucional & 53 & $38.7 \%$ \\
Falta de interés de los alumnos & 40 & $29.2 \%$ \\
Falta de tiempo & 75 & $54.7 \%$ \\
Total & 137 & $100 \%$ \\
\hline
\end{tabular}

Finalmente, se pretende conocer el nivel de conocimiento y formación recibida por parte del profesorado. En relación a sus conocimientos (Véase Tabla 6), las personas encuestadas dicen ser expertos en el manejo del correo electrónico $(60,8 \%)$, el procesador de texto $(59,9 \%)$, en buscadores como Goggle, Yahoo, ... (58.7\%), programas de presentación (45\%) y servicios como Dropbox para trabajar con documentos en la red (40.65\%). Sin embargo, afirman tener un conocimiento solo moderado en Sistemas operativos como Windows, Linux, Mac... (63.6\%), programas de presentaciones como PowerPoint, Prezi,...(53.8\%), hojas de cálculo (44.8\%), uso de la página web de la universidad y uso pedagógico de las TIC, ambos con (41.3\%) y diseño de materiales multimedia (35\%). En lo que afirman no tener ningún conocimiento es en realidad aumentada (89.5\%), la creación de videojuegos educativos y mantenimiento del PC, ambos con (55.9\%), diseño de objetos de aprendizaje y uso de simuladores, ambos con (55.2\%), manejo de imágenes (49\%), creación de wikis (41.3\%), diseño de materiales multimedia (38.5\%) o diseño de blogs (37.8\%). 
Tabla 6. Frecuencias y porcentajes de la variable "Nivel de conocimiento que tiene de las herramientas TIC"

\begin{tabular}{|c|c|c|c|c|c|c|c|c|}
\hline & $\mathrm{Ni}$ & Ino & & mo & $\mathrm{Mc}$ & rado & & erto \\
\hline & $f$ & $\%$ & $f$ & $\%$ & $f$ & $\%$ & $f$ & $\%$ \\
\hline stemas operativos (Windows, Linux). & 2 & 1.4 & 15 & 10.5 & 91 & 63.6 & 35 & 24.5 \\
\hline Procesadores de texto (Word,...). & 0 & 0 & 1 & 0.7 & 62 & 43.4 & 80 & 55.9 \\
\hline $\begin{array}{l}\text { Programas de presentaciones (Power- } \\
\text { Point, Prezi,...). }\end{array}$ & 0 & 0 & 1 & 0.7 & 77 & 53.8 & 65 & 45.5 \\
\hline Bases de datos (Access, Sql, MySql...). & 36 & 25.2 & 21 & 14.7 & 51 & 35.7 & 35 & 24.5 \\
\hline Hojas de cálculo (Excel...). & 10 & 7 & 13 & 9.1 & 64 & 44.8 & 56 & 39.2 \\
\hline Diseño de objetos de aprendizaje. & 79 & 55.2 & 25 & 17.5 & 30 & 21 & 9 & 6.3 \\
\hline $\begin{array}{l}\text { Diseño de blogs (blogger, Wordpress, } \\
\text {...). }\end{array}$ & 54 & 37.8 & 28 & 19.6 & 46 & 32.2 & 15 & 10.5 \\
\hline $\begin{array}{l}\text { Diseño de materiales multimedia (pre- } \\
\text { sentaciones, video, audio...). }\end{array}$ & 55 & 38.5 & 22 & 15.4 & 50 & 35.0 & 16 & 11.2 \\
\hline Manejo de imágenes (Photoshop, ....) & 70 & 49.0 & 24 & 16.8 & 38 & 26.6 & 11 & 7.7 \\
\hline Creación de videojuegos educativos,...) & 80 & 55.9 & 28 & 19.6 & 29 & 20.3 & 6 & 4.2 \\
\hline Recursos Educativos Abiertos & 75 & 52.4 & 16 & 11.2 & 32 & 22.4 & 20 & 14.0 \\
\hline Mantenimiento de PC & 80 & 55.9 & 30 & 21 & 28 & 19.6 & 5 & 3.5 \\
\hline Instalación de software en un PC & 51 & 35.7 & 18 & 12.6 & 30 & 21 & 44 & 30.8 \\
\hline Uso de simuladores & 79 & 55.2 & 22 & 15.4 & 27 & 18.9 & 15 & 10.5 \\
\hline Tecnología educativa & 48 & 33.6 & 26 & 18.2 & 50 & 35 & 19 & 13.3 \\
\hline Educación virtual, educación a distancia & 42 & 29.4 & 20 & 14.0 & 55 & 38.5 & 26 & 18.2 \\
\hline Uso pedagógico de las TIC & 32 & 22.4 & 25 & 17.5 & 59 & 41.3 & 27 & 18.9 \\
\hline $\begin{array}{l}\text { Herramientas de comunicación (Correo } \\
\text { electrónico, listas de distribución, men- } \\
\text { sajería instantánea,...). }\end{array}$ & 3 & 2.1 & 3 & 2.1 & 50 & 35 & 87 & 60.8 \\
\hline $\begin{array}{l}\text { Uso de Navegadores (Mozilla, Chro- } \\
\text { me,...) }\end{array}$ & 7 & 4.9 & 5 & 3.5 & 58 & 40.6 & 73 & 51 \\
\hline Uso de buscadores (google, yahoo,...). & 1 & 0.7 & 6 & 4.2 & 52 & 36.4 & 84 & 58.7 \\
\hline $\begin{array}{l}\text { Trabajo con documentos en la red (goo- } \\
\text { gle docs, dropbox,...). }\end{array}$ & 17 & 11.9 & 12 & 8.4 & 56 & 39.2 & 58 & 40.6 \\
\hline $\begin{array}{l}\text { Construcción de mapa conceptual } \\
\text { (cmaptool, mindomo, maindmaster,...). }\end{array}$ & 44 & 30.8 & 15 & 10.5 & 49 & 34.3 & 35 & 24.5 \\
\hline $\begin{array}{l}\text { Creación de Wikis (wikipedia, wikispa- } \\
\text { ces,..) }\end{array}$ & 59 & 41.3 & 31 & 21.7 & 37 & 25.9 & 16 & 11.2 \\
\hline Uso de Realidad aumentada. & 128 & 89.5 & 6 & 4.2 & 9 & 6.3 & 0 & 0 \\
\hline $\begin{array}{l}\text { Uso de redes sociales (LinkedIn, Face- } \\
\text { book) }\end{array}$ & 21 & 14.7 & 14 & 9.8 & 60 & 42 & 48 & 33.6 \\
\hline $\begin{array}{l}\text { Manejo de plataformas educativas, } \\
\text { (Blackboard, Moodle,...). }\end{array}$ & 33 & 23.1 & 14 & 9.8 & 55 & 38.5 & 41 & 28.7 \\
\hline Uso de la página web de la Universidad & 24 & 16.8 & 10 & 7 & 59 & 41.3 & 50 & 35 \\
\hline $\begin{array}{l}\text { Uso de los recursos electrónicos dispo- } \\
\text { nibles en la página web de biblioteca de } \\
\text { la Universidad (bases de datos, catálogo } \\
\text { en línea,...) }\end{array}$ & 35 & 24.5 & 12 & 8.4 & 53 & 37.1 & 43 & 30.1 \\
\hline
\end{tabular}


En relación a la formación recibida (Véase Figura 2), la mitad del profesorado, con un $51.8 \%$, afirma haber recibido una formación muy suficiente o suficiente, mientras que el $32.2 \%$ considera que ha sido insuficiente y un $16.1 \%$ dice no haber recibido formación alguna. Con respecto a la duración formativa (Véase Figura 3), un alto porcentaje de los encuestados, concretamente, un $33.6 \%$ no respondieron a esta pregunta. Entre aquellas personas que si respondieron, el $28.7 \%$ afirmaron que su formación tuvo una duración de dos o más meses, el 25.2\% recibió una formación menor de 20 horas y el $12.6 \%$ recibió formación de 20 horas.

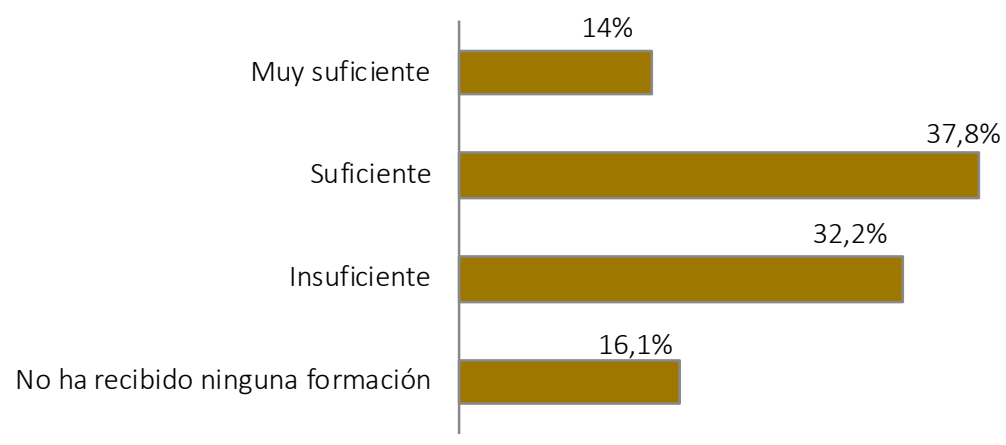

Figura 2. Porcentajes de frecuencias en la variable "Formación en TIC"

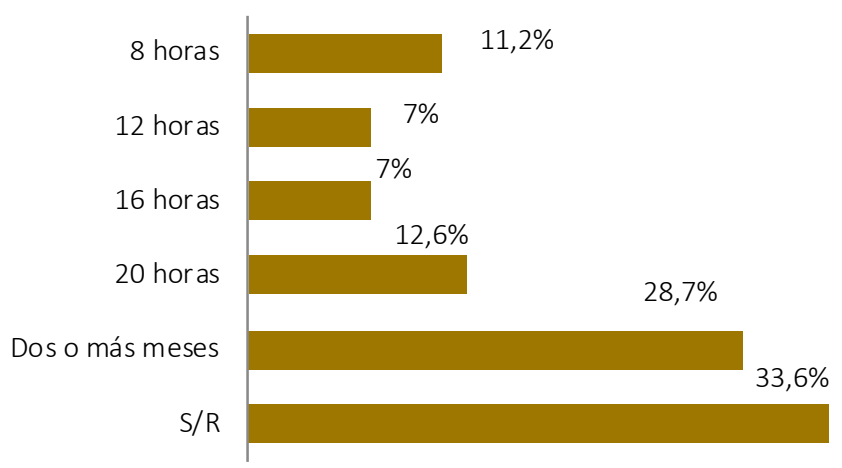

Figura 3. Porcentajes de frecuencias en la variable "Tiempo de formación"

Aunque un gran porcentaje del profesorado, el $77.3 \%$, han adquirido sus conocimientos de forma autodidacta, un $66.4 \%$ afirma haberse formado en la universidad, el $25.5 \%$ se ha formado tomando cursos en línea, el $18.2 \%$ en instituto especializado, el $17.3 \%$ en otras universidades, el $9.1 \%$ en el extranjero (Véase Figura 4). Así mismo, se puede apreciar en la Figura 5 el 
tiempo transcurrido desde la última formación. El 58.7\% recibió su formación durante el periodo del 2010 al 2013, el 8.4\% las tomó del 2005 al 2010, y el 3.5\% se capacitó antes del 2005. El porcentaje restante, el $29.4 \%$, no contestó a dicha cuestión.

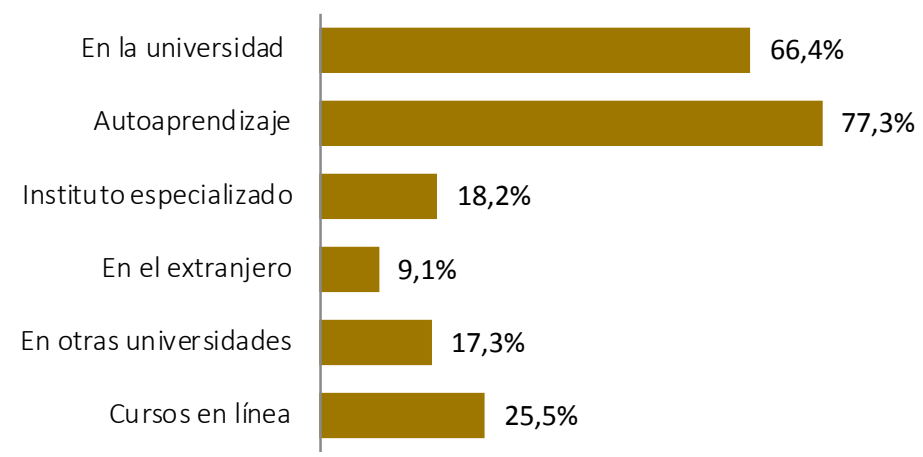

Figura 4. Porcentajes de frecuencias en la variable "Lugar en el que recibieron formación"

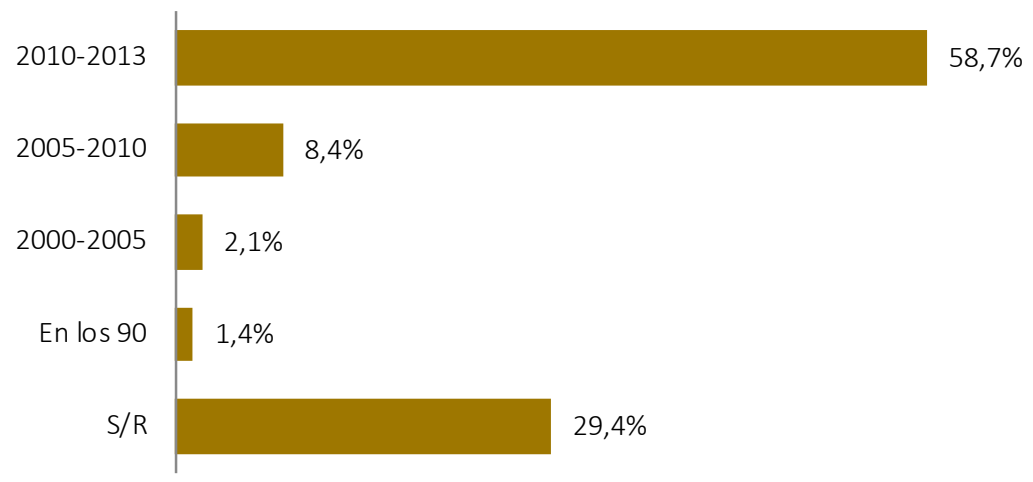

Figura 5. Porcentajes de frecuencias en la variable "Periodo última formación recibida"

En referencia a la frecuencia con que utilizan lo aprendido en su práctica docente (Véase Figura 6), y teniendo en cuenta aquellos/ as profesores/as que respondieron, el $60.2 \%$ afirma utilizarlo siempre 0 casi siempre, mientras que el $16.1 \%$ afirma que lo utiliza algunas veces o nunca. Con respecto al grado de dificultad en el aprendizaje de las TIC (Véase Figura 7), el 55.3\% del profesorado expone que les resultó fácil o muy fácil, mientras que el $21.7 \%$ considera que el aprendizaje de las TIC les supuso cierta dificultad. 


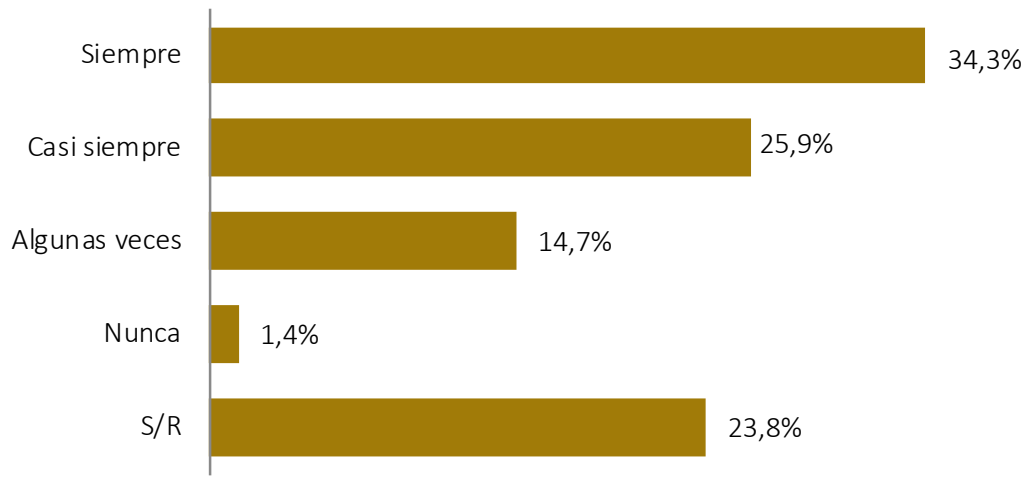

Figura 6. Porcentajes de frecuencias obtenidos en la variable "Frecuencia sobre la aplicabilidad dificultad de lo aprendido en su práctica docente"

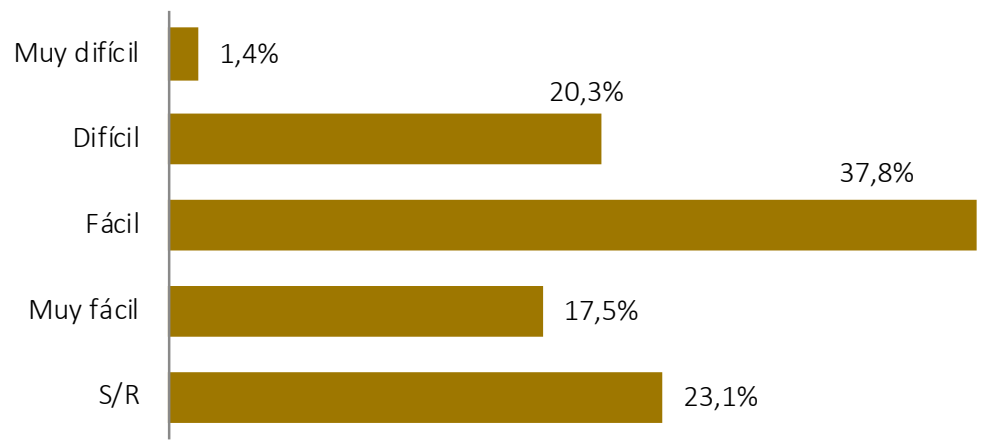

Figura 7. Porcentajes de frecuencias obtenidos en la variable "Grado de en el aprendizaje de las TIC"

Aquel profesorado que ha manifestado que el proceso formativo había sido fácil (Véase Figura 8), expusieron entre sus motivos: tener una actitud positiva (70.8\%), las prácticas realizadas le ayudó en su formación (59,6\%), los conocimientos previos que tenían sobre TIC los ayudó a tener un mejor aprendizaje (51.7\%), la metodología utilizada por los formadores (40.4\%) y en menor medida, su autoaprendizaje (22.5\%). En contraposición, aquellos que afirman haber encontrado dificultades, exponen entre sus motivos y que podemos apreciar en la Figura 9, la falta de tiempo para practicar lo aprendido (75.4\%). Seguidamente, los encuestados exponen la falta de atención personalizada (47.5\%), la falta de conocimientos previos $(42.6 \%)$, el ritmo de la enseñanza $(36,1 \%$ ) y dificultades técnicas $(31,1 \%)$. En menor medida, el profesorado hace referencia al temor o inseguridad por su parte (16.4\%) y ordenadores insuficientes $(8.2 \%)$ 


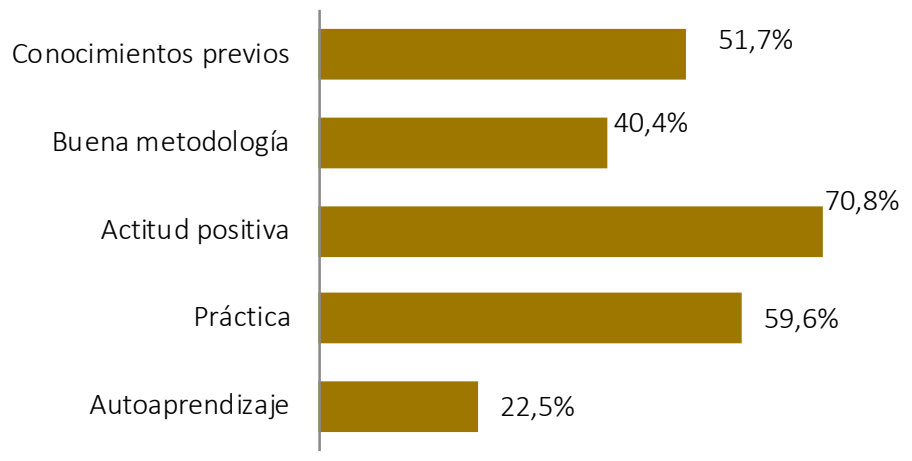

Figura 8. Porcentajes de frecuencias obtenidos en la variable "Causas de la facilidad"

Falta de tiempo para practicar y horarios poco flexibles

Dificultades técnicas

Computadoras insuficientes

Temor e inseguridad

Falta de atención personalizada

Ritmo de la enseñanza

La metodología

Falta de conocimientos previos

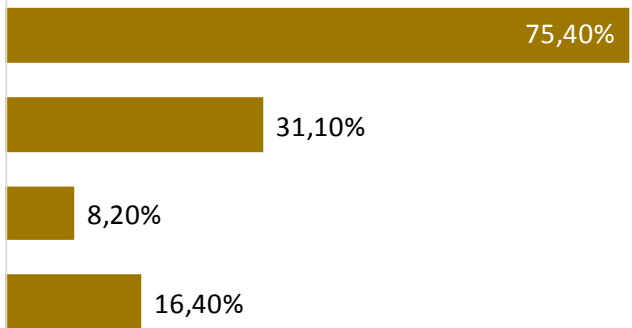

$47,50 \%$

$36,10 \%$

$21,30 \%$

$42,60 \%$

Figura 9. Porcentajes de frecuencias obtenidos en la variable "Causas de la dificultad"

Las principales dificultades por las que no se suelen formar los encuestados (Véase Figura 10) son; la falta de tiempo ( $f=76 ; 72.4 \%$ ) y la falta de apoyo técnico e institucional ( $f=69 ; 65.7 \%)$, siendo causas menores “poca motivación e interés' por su parte (12,4\%). 


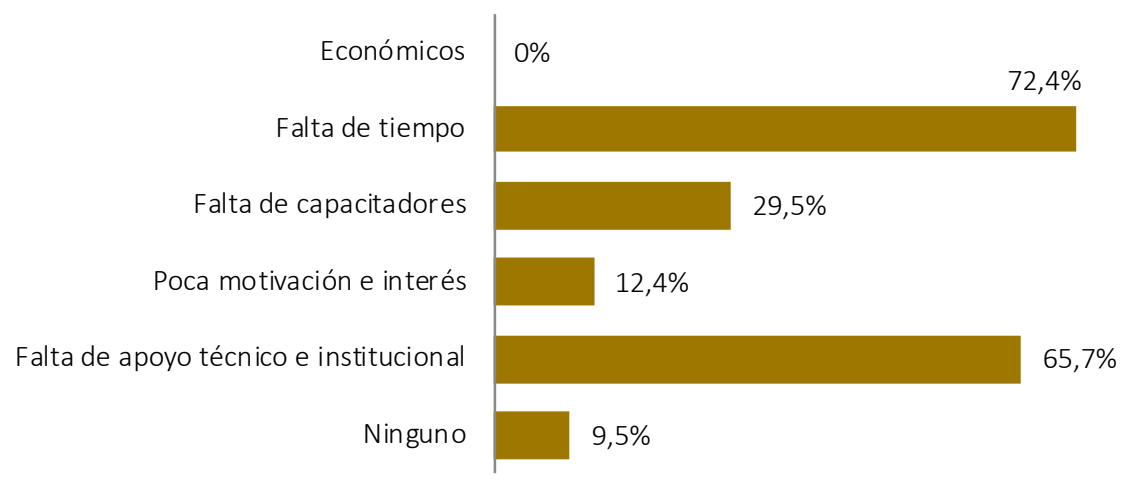

Figura 10. Porcentajes de frecuencias obtenidos en la variable "Obstáculos que ha encontrado en su proceso de formación en TIC"

Con respecto a la entrevista, las dimensiones que obtienen mayores porcentajes son: "Uso didáctico de las TIC" (35.8\%) y "Formación y necesidades formativas en TIC del profesorado" (31.4\%) seguido de las otras dos dimensiones "Disponibilidad de TIC en la universidad" (16.6\%), y "Actitudes hacia las TIC" (16.2\%). Con respecto a la Dimensión "Disponibilidad de TIC en la universidad "las personas entrevistadas exponen que aunque la universidad posee una infraestructura tecnológica con equipamientos, software, internet en todas las aulas, esta no es suficiente, ya que los recursos no están actualizados y el apoyo institucional se ha reducido en los últimos tiempos. En la segunda dimensión, "Uso didáctico de las TIC", la mayor preocupación o principales barreras expuestas son la falta de capacitación docente para utilizarlas y la falta de tiempo para llevar a cabo dicha formación. Con respecto a la dimensión "Formación y necesidades formativas en TIC del profesorado" se confirma que la universidad ofrece formación, pero centrada principalmente en los aspectos técnicos, olvidando lo fundamental, el aspecto didáctico y pedagógico. Finalmente, y en relación a la dimensión "Actitudes hacia las TIC", el profesorado considera que ayudan a facilitar el proceso de enseñanza y aprendizaje, les permite trabajar mejor con los alumnos, aunque también reconocen que sus escasos conocimientos le provocan desmotivación y reticencia a la hora de utilizarlas.

En cuanto a "Ios recursos tecnológicos disponibles" a nivel personal por el profesorado, en la Tabla 7, se puede apreciar en orden decreciente que, el $66.4 \%$ del profesorado tienen ordenadores de sobremesa, el $93.7 \%$ tienen portátiles, el $46.9 \%$ tiene tableta y el $9.8 \%$ posee lector electrónico. Además, el $100 \%$ posee teléfono con conexión a Internet, por lo que el profesorado cuenta con recursos tecnológicos suficientes para llevar a la práctica su formación en TIC. 
Tabla 7. Porcentajes de respuestas obtenidos de la variable "Recursos tecnológicos disponibles"

\begin{tabular}{lcc}
\hline & Frecuencia (f) & Porcentaje (\%) \\
\hline Ordenador de sobremesa & 95 & $66.4 \%$ \\
Portátiles (laptop, mini laptop) & 134 & $93.7 \%$ \\
Tablet, Ipad & 67 & $46.9 \%$ \\
Lector electrónico (ereader Kindle, Nook) & 14 & $9.8 \%$ \\
Dispositivo móvil & 143 & $100 \%$ \\
Conexión a Internet & 143 & $100 \%$ \\
Total & 596 & $416.8 \%$ \\
\hline
\end{tabular}

En relación al "Iugar desde donde acceden" y cómo podemos observar en la Figura 11, el 100\% del profesorado encuestado acceden desde sus casas, el $88.1 \%$ pueden acceder desde la oficina, el $52.4 \%$ en los laboratorios de la universidad, el $54.5 \%$ en el salón de profesores y el $30.8 \%$ en cualquier lugar donde haya conexión WiFi. Este es un dato muy importante, porque el profesorado puede darle seguimiento a sus capacitaciones en TIC, independientemente del lugar donde se encuentren.

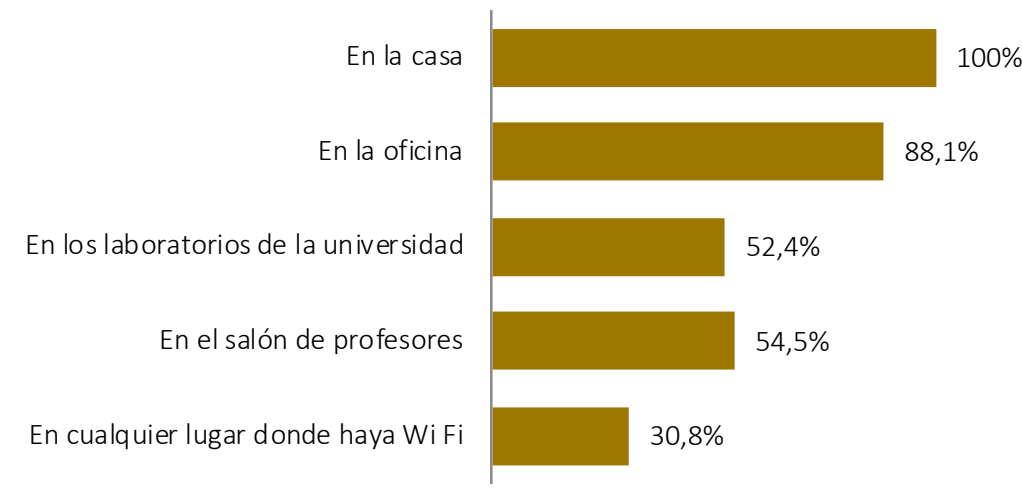

Figura 11. Porcentajes de frecuencias obtenidos en la variable "Lugar desde donde acceden"

\section{CONCLUSIONES}

A pesar de contar con recursos tecnológicos en la universidad, el profesorado se encuentra con importantes dificultades con respecto a la red wifi, hardware y software obsoletos, la falta de apoyo técnico e institucional, así como la falta de visión de las autoridades. Consideramos de gran importancia resaltar la elevada necesidad de formación detectada entre el profesorado, tanto a nivel técnico como pedagógico. Las herramientas utilizadas en el proceso educativo son básicamente tradicionales, por lo que el uso de las herramientas web 2.0 entre los encuestados es inexistente, ya que su escasa 
formación limita la confianza en el profesorado a utilizarlas con su alumnado, considerándose a sí mismo como no competente para ello. Un ejemplo se percibe en el uso del móvil, el cual no es visto por el profesorado como una herramienta apta para el proceso de enseñanza-aprendizaje. Esto conlleva un uso de las TIC para transmitir información y no para investigar, colaborar, analizar, etc... como nos comentaba (Poore, 2013), aspectos fundamentales en los tiempos actuales para enfrentar los retos y desafíos de aprendizaje del siglo XXI y que permitiría que el alumnado construyera su conocimiento. Un uso inadecuado como consecuencia de la escasa formación recibida, la cual expusieron ser breves y centrada en aspectos técnicos. Una puesta en práctica que no coincide con los propósitos de uso mencionado por el profesorado, entre los que destacaban: motivar a los estudiantes, clarificar conceptos, retroalimentar, propiciar el autoaprendizaje e implementar una metodología más creativa. Otro de los factores que influyen en el uso de las TIC es la falta del tiempo, ya que requiere una mayor dedicación y trabajo por parte del profesorado que con las estrategias tradicionales, unos resultados que coinciden con el estudio realizado por (Bingimlas, 2009). Asimismo, es evidente que no se pone en práctica un Diseño Universal para el Aprendizaje, aspecto fundamental para una educación de calidad, en la que "no podemos pedir que todos aprendan lo mismo, de la misma forma, en el mismo tiempo, mismos recursos, por lo que tendremos que tener en cuenta sus diferencias y ofrecer los recursos y metodologías que más se ajusten a sus necesidades y donde las tecnologías constituyen un eje fundamental para alcanzar dicho objetivo" (Aguilar y Benítez, 2017, p.8).

Para cerrar y como aspecto positivo, la mayoría de los docentes tiene una actitud positiva hacia el uso de las TIC en el proceso de enseñanza y aprendizaje. Unos resultados que coinciden con el estudio realizado por Abella, Hortigüela, Pérez-Pueyo y Salicetti (2016) y hace constatar que con la formación adecuada se podría alcanzar un uso diferente al que se ha venido haciendo hasta ahora.

\section{Referencias bibliográficas}

Abella, V., Hortigüela, D., Pérez-Pueyo, Á. y Salicetti, A. (2016). Actitudes de los futuros educadores hacia la integración de las TIC en la docencia. En P. Membiela, N. Casado y M. I. Cebreiros (Coords.). Nuevos escenarios en la docencia universitaria: Novos escenarios da docencia universitaria (pp. 169-174). Educación Editora. Accesible en https://bit.ly/2U39jzm

Aguilar, S. y Benítez, R. (2017). Investigando desde una perspectiva inclusiva el uso de las TIC como recurso de acceso al aprendizaje y atención a la diversidad del alumnado mayor. El profesorado universitario y su formación en diseño universal de aprendizaje. 
En J. Ruiz-Palmero, J. Sánchez-Rodríguez y E. Sánchez-Rivas, (Edit.), Innovación docente y uso de las TIC en educación (1-10). Málaga: UMA.

Albert, M.J. (2006). La investigación educativa: claves teóricas. Madrid: McGraw-Hill.

Angulo, J., García, R.I., Torres, C.A., Pizá, R.I. y Ortíz, E.R. (2015). Nivel de Logro de Competencias Tecnológicas del Profesorado Universitario. International Multilingual Journal of Contemporary Research, 3(1), 67-80.

Arancibia, M., Valdivia, I., Araneda, S. y Cabero, J. (2017). Tipologías para la Innovación tecnológica en Docentes de Educación Superior a partir de un análisis de conglomerados: un estudio exploratorio. RED. Revista de Educación a Distancia, 55, 1-21.

Arancibia, M., Cosimo, D. y Casanoba, R. (2018). Percepción de los profesores sobre integración de TIC en las prácticas de enseñanza en relación a los marcos normativos para la profesión docente en Chile. Ensaio, Avaliação e Políticas, em Educação, 98(26). Recuperado de: http://dx.doi.org/10.1590/s0104-40362017002501119

Area, M. y Guarro, A. (2012). La alfabetización informacional y digital: fundamentos pedagógicos para la enseñanza y el aprendizaje competente. Revista española de documentación científica, 35, 46-74.

Balanskast, A. y Blamire, R. (2007). ICT in Schools: Trends, innovations and issues in 20062007. Recuperado de: https://bit.ly/2G4Zegj

Barrera-Osorio, F. y Linden, L. (2009). The use and misuse of computers in education: evidence from a rando- mized experiment in Colombia. Washington, DC: World Bank.

Barroso, J.M. y Padrón, M.C. (2014). Competencias tecnológicas básicas de los docentes que inician la formación en la mención matemática de la face-uc. Revista de Tecnología de Información y Comunicación en Educación, 8(2), 25-40.

Barroso, J. y Cabero, J. (2010). La investigación educativa en TIC. Visiones prácticas. Madrid: Síntesis.

Bingimlas, K.A. (2009). Barriers to the successful integration of ICT in teaching and learning environments: A review of the literature. Eurasia Journal of Mathematics, Science \& Technology Education, 5(3), 235-245.

Buckingham, S. y Ferguson, R. (2012). Social Learning Analytics. Educational Technology and Society, 15(3), pp. 3-26.

Cabero, J. (2004). Formación del profesorado en TIC. El gran caballo de batalla. Comunicación y Pedagogía: Nuevas tecnologías y recursos didácticos, 195, 27-31.

Cabero, J. (2014). La formación del profesorado en TIC: modelo TPACK. Sevilla: Grupo de Investigación Didáctica.

Cabero, J. y Barroso, J. (2013). La utilización del juicio de experto para la evaluación de TIC: el coeficiente de competencia experta. Bordon, 65(2), 25-38.

Cabero, J. y Marín, V. (2013). Valoración del entorno formativo universitario DIPRO 2.0. Profesorado. Revista de Currículum y Formación de Profesorado, 17 (2), 369-383.

Cabero, J. y Barroso, J. (2016). Formación del profesorado en TIC: una visión del modelo TPACK. Cultura y Educación, 28(3), 633-663.

Carrera, F.X. y Coiduras, J.L. (2012). Identificación de la competencia digital del profesor universitario: un estudio exploratorio en el ámbito de las ciencias sociales. REDU. 
Revista de Docencia Universitaria, 10(2), 273-298. Recuperado de https://bit. Iy/2IsiPtp.

Cejas, R., Navío, A. y Barroso, J. (2016). Las competencias del profesorado universitario desde el modelo TPACK (conocimiento tecnológico y pedagógico del contenido). Pixel-Bit. Revista de Medios y Educación, 49, 105-119.

Díaz, J.J. (2017). Análisis del Aprendizaje Social en la Educación Superior: antecedentes y líneas de actuación futuras. Revista Educativa Hekademos, 22, Año X, 93-104.

European Commission (2008). The education and training contribution to the Lisbon strategy. Recuperado de: http://ec.europa.eu/education/policies/2010/et_2010_en.html

Federico, A. y Agresti, P. (2017). Sociedad y estado en el mundo actual. Buenos Aires: Eudeba.

Gray, L. y Lewis, L. (2009). Educational Technology in Public School Districts: Fall 2008 (NCES 2010 - 003). NCES, Institute of Education Sciences, U.S. Washington, DC.: Department of Education.

Gutiérrez, I. (2014). Perfil del profesorado español en torno a las competencias en tecnologías de la información y la comunicación. Pixel Bit. Revista de Medios y educación, 44, 51-65.

Johnson, L., Adams, S., Cummins, M., Estrada, V., Freeman, A. y Ludgate, H. (2013). NMC Horizon Report: 2013 Higher Education Edition. Austin, Texas: The New Media Consortium.

Johnson, L., Adams, S., Estrada, V. y Freeman, A. (2014). NMC Horizon Report: 2014 Higher Education Edition. Austin, Texas, Estados Unidos: The New Media Consortium.

Kaya, Z., Emre, I. y Kaya, O. (2013). Adaptation of Technological Pedagogical Content Knowledge Scale to Turkish. Theory \& Practice, 13 (4), 2367-2375.

Leiva, J.P., Ugalde, L., Llorente-Cejudo, C. (2018). El modelo TPACK en la formación inicial de profesores: modelo Universidad de Playa Ancha (UPLA), Chile. Pixel Bit. Revista de Medios y educación, 53, 165-177.

Llorente-Cejudo, M.C. (2008). Aspectos fundamentales de la formación del profesorado en tic. Pixel-Bit. Revista de Medios y Educación, 31, 121-130.

Marín, V., Cabero, J. y Barroso, J. (2014). Evaluando los entornos formativos online. Redu. Revista de Docencia Universitaria, 12(2), 375-399.

Martínez, M., López-Martín, R. y Pérez-Carbonell, A. (2018). E-innovación en educación superior. Claves para la institucionalización en las universidades. Píxel-Bit. Revista de Medios y Educación, 52, 1133-8482.

Mishra, P. y Koehler, M. J. (2006). Technological pedagogical content knowledge: A framework for teacher knowledge. Teachers college record, 108(6), 1017-1054.

Pastor, C.A. (2012). Aportaciones del Diseño Universal para el Aprendizaje y de los materiales digitales en el logro de una enseñanza accesible. En J. Navarro, Ma ${ }^{a}$.T. Fernández, F.J. Soto y F. Tortosa (Coords.) (2012), Respuestas flexibles en contextos educativos diversos (1-13). Murcia: Consejería de Educación, Formación y Empleo.

Pérez, A. (2012). Educarse en la era digital: la escuela educativa. Madrid: Morata.

Prendes, M.P. y Gutiérrez, I. (2013). Competencias tecnológicas del profesorado en las Universidades españolas. Revista de Educación, 361. Recuperado de: https://bit. Iy/2VzW3DN. 
Poore, M. (2013). Using social media in the classroom. London: Sage.

Pozos, K.V. (2015). Evaluación de necesidades de formación continua en Competencia Digital del Profesorado Universitario mexicano para la Sociedad del Conocimiento. (Tesis Doctoral). Depto. Pedagogia Aplicada, Universitat Autònoma de Barcelona.

Roig, R. y Flores, C. (2014). Conocimiento tecnológico, pedagógico y disciplinario del profesorado: el caso de un centro educativo inteligente. EDUTEC, Revista Electrónica de Tecnología Educativa, 47. Recuperado de https://bit.ly/2uTxEgD

Rojas-Castro, P. (2017). Learning Analytics. Una revisión de literatura. Educación y educadores, 20(1), 106-128. https://doi.org/10.5294/edu.2017.20.1

Sabariego, M. (2004). El proceso de investigación. En R. Bisquerra (coord.), Metodología de la investigación educativa (127-163). Madrid: La Muralla.

Siemens, G y Long, P. (2013). Penetrating the Fog: Analytics in Learning and Education. Educause Review, 46, 31-40. https://bit.ly/1xIMCED.

Suárez-Rodríguez, J.M., Almerich, G., Díaz-García, I. y Fernández-Piqueras, R. (2012). Competencias del profesorado en las TIC. Influencia de factores personales y contextuales. Universitas Psychologica, 11(1), 293-309.

Tejedor, F.J., García-Valcárcel A. y Prada, S. (2009). Medida de actitudes del profesorado universitario hacia la integración de las TIC. Comunicar. Revista Científica de Educomunicación, 33, 115-124. https://doi.org/10.3916/c33-2009-03-002 